\title{
$\checkmark$ \\ Boas novas de Babel pela Internet
}

\author{
$\underline{\text { Sergio Caparelli }}$ \\ UFRGS
}

As bibliotecas têm a imponência do saber nelas contido. E cada usuário guarda dentro de si uma imagem palpável de estantes e de livros, de lombadas que se sucedem indefinidamente. Também os arquivos. Visitando um tribunal de contas, um fórum ou o acervo de um escritor, as pessoas têm seu cotidiano repentinamente tomado pela memória, dos outros e dele mesmo, memórias em bits, memórias em átomos, memórias em memórias, já que livro algum começa em si mesmo.

Mais recentemente os computadores transpuseram livros e arquivos para uma rede de saber. De repente, diz-se, os átomos transformaram-se em bits, construindo um universo virtual, novo e fascinante. O espaço se contraiu e na sua contração regurgitou o tempo, único para alguns, descontínuo para outros mas, para todos, denso de trocas simbólicas.

Existem também bibliotecas e arquivos reconstruídos pelo imaginário. Cada um tem a sua biblioteca particular, suas galerias com livros obscuros, suas prateleiras, sua memória. Os economistas reconstroem as bibliotecas com gráficos, orçamentos; governantes, com réguas, compassos políticos; os poetas, com educação pela pedra ou pela emoção. No caso da literatura, talvez fosse o tempo de alguém fazer um estudo desses imaginários. Que tipo mesmo de arquivo tinha Kafka? E as estantes de $O$ nome da rosa? E os livros calcinados da Biblioteca de Alexandria? O Brasil colonial nos arquivos da Torre do Tombo? Ou então, imaginários mais recentes, de bibliotecas que não existem mas que disponibilizam o conhecimento que existe, na grande rede dos olhos sobre a tela, dos dedos sobre o teclado, formando sinapses indescritíveis.

No nosso trabalho, esses imaginários serão apenas ponto de partida e ponto de chegada. Iniciando com duas citações, deixo a 
vocês a escolha quanto a sua veracidade e quanto a sua propriedade. Ambas, segundo consta, fazem parte de um dos axiomas da maior das bibliotecas jamais criadas: o axioma de que o homem empreende uma busca permanente da biblioteca total, aquela que contenha tudo o que é dado a expressar em todos os idiomas. Inicio a primeira citação sobre essa biblioteca:

“(...) constitui-se de um número indefinido, e talvez infinito, de galerias hexagonais, com vastos poços de ventilação no centro, cercados por varandas baixíssimas. De qualquer hexágono, vêemse os pisos inferiores e superiores: interminavelmente. A distribuição das galerias é invariável. Vinte estantes, em cinco longas prateleiras por lado, cobrem todos os lados menos dois; sua altura, que $e$ a dos andares, excede apenas a de um bibliotecário normal. Uma das frentes livres leva a um saguão estreito, que desemboca em outra galeria, idêntica à primeira e a todas. Â esquerda e à direita do saguão, há dois sanitários minúsculos. Um permite dormir em pé; outro, satisfazer as necessidades fecais. Por aí passa a escada espiral que se abisma e se eleva para o longe. No saguão há um espelho, que duplica as aparências fielmente. Os homens costumam inferir desse espelho que a Biblioteca não $e$ infinita (se o fosse realmente, para que essa duplicação ilusória?), prefiro imaginar que as superficies polidas representam e prometem o infinito" (Borges, 1976, p. 61 e 62).

Passo à segunda, sobre o arquivamento de uma mulher, depois de seu corpo ter sido cortado em partes de um terço de milímetro cada, das quais foram feitas 5.200 imagens.

"As imagens vão ser programadas e assim parecerão se mover, tornando-se, a mulher, mais jovem ou mais velha. Isso vai tornar possivel aos estudantes de medicina praticarem cirurgias, trabalhando com aparelhos cirargicos interativos. As imagens poderão ser combinadas de diferentes formas. Assim o corpo e os orgāos poderão ser vistos de qualquer ângulo, dissecados e reunidos novamente. Essa mulher tem 45 gigabites e equivale a 32 mil disquetes. A Biblioteca Nacional onde a mulher foi arquivada está distribuindo as imagens em CD ROM, ao preço de aproximadamente 700 d6lares." (Electronic Telegraph,30 nov 1995).

A primeira citação é de Jorge Luis Borges e constitui o início de uma descrição da Biblioteca de Babel: quando se proclamou que essa Biblioteca abarcava todos os livros, a primeira impressão foi de extravagante felicidade, pois os homens sentiram-se proprietários de um tesouro intacto e secreto. A segunda é uma 
notícia disponível no Electronic Telegraph, de Londres, de 30 de novembro de 1995.Trata-se de uma mulher que havia morrido de ataque de coração, encontrando a imortalidade no ciberespaço: seu marido doou seu corpo para o Visible Human Project, da Biblioteca Nacional de Medicina dos Estados Unidos, e ela é a primeira mulher virtual à disposição de todos aqueles que tenham 700 dólares para adquiri-la.

Se deixarmos de lado que o primeiro relato foi feito por Borges e o segundo por um jornalista inglês, não seria de todo absurdo acreditar que a biblioteca do desejo imaginada em Babel é muito menos fantasiosa do que a do arquivo de homens e de mulheres vendidos a 700 reais em CD-ROM. Claro, a biblioteca de Babel não é apenas uma biblioteca. $O$ início da citação pretende que "o universo (que outros chamam a Biblioteca) constitui-se de um número indefinido, e talvez infinito, de galerias hexagonais". Nessa caso, a biblioteca é apenas uma metáfora, uma imagem em que a verdadeira Babel é a humanidade. Por outro lado, tendências recentes no desenvolvimento das indústrias da informação mostram que homens e mulheres arquivados e postos à venda são tanto uma metáfora - questão de estilo - como também se inscrevem numa economia política que mercantiliza até o ciberespaço.

Nossa intenção, aqui, é refletir sobre tendências recentes que vêm possibilitando o acesso às bibliotecas e bancos de dados, uma previsão de que esse tipo de comunicação em rede tenderá cada vez mais a seguir a lógica de mercado e que, diferente de outros setores do audiovisual, levará a lógica da exclusão também para as bibliotecas, especialmente para as bibliotecas públicas. Por último, levantaremos algumas questões sobre essa situação em sociedades fora do eixo desenvolvido, ressaltando que seria reforçada essa lógica da exclusão, mesmo que esse tipo de comunicação traga beneficios de outra ordem.

\section{Imagens da produção}

Assistimos hoje às transformações decorrentes da revolução da micro-eletrônica, das mudanças na informática, na biotecnologia e nas telecomunicações. Vamos nos deter, porém, em algumas mudanças ocorridas a partir dos anos 70, com a convergência das telecomunicaçōes, da comunicação e da informática. Setores que até então tinham uma história separada convergem para um ponto único. As grandes empresas de telecomunicaçōes com interesse 
apenas no transporte de sinais, sem se interessar pelo conteúdo, passam a investir em conteúdos, participando de produtoras de audiovisuais; empresas de comunicação que antes se interessavam pelo conteúdo passam a investir também no transporte de sinais, tudo isso permeado pela informática. Uma análise dos conglomerados para a exploração de televisão a cabo no Brasil ou nas privatizações da Cia. Rio Grandense de Telecomunicações, no Rio Grande do Sul, ou do leilão para exploração da Banda B de telefonia em São Paulo, confirmam essas tendências.

Essa revolução tecnológica torna possivel e cada vez mais barato transmitir tudo - textos, imagens, sons - em grandes volumes e com rapidez. Os países e as cidades se transformam. Criam-se assim, espaços hegemônicos, áreas densas de ciência, tecnologia e informação, onde a carga de racionalidade é maior, atraindo açōes racionais de interesse global em contraposição a espaços hegemonizados, distantes desta mesma lógica (Santos, 1996b). A dicotomia entre a cidade e o campo vai perdendo a sua importância. A partir desse momento, torna-se possivel, segundo Dowbor (1995, p. 21),

a) estocar de forma prática, em disquetes, em discos rígidos e em discos laser, gigantescos volumes de informação;

b) trabalhar esta informação de forma inteligente, permitindo a formação de banco de dados sociais e individuais de uso simples e prático;

c) transmitir a informação através do telefone conectado ao computador, de forma barata e precisa, inaugurando uma nova era de comunicação de conhecimentos;

d) integrar a imagem fixa ou animada, o som e o texto de maneira muito simples, e com custos reduzidos.

Essa facilidade, caracterizada pela compressão do tempo e do espaço (Harvey, 1994), possibilitando tanto uma reorganização do sistema financeiro global como uma consulta on line a alguma das bibliotecas nas metrópoles mundiais ou, por exemplo, a 1400 jornais diários e suas centenas de conexões apenas num único site da Internet (www.mediainfo.com), dão a impressão de que 1) essas informações, jornais ou livros são apenas virtuais e 2) levitam num espaço paralelo que alguns denominam noosfera; 3) à disposição de qualquer pessoa que tenha um computador em casa, uma linha telefônica e um provedor.

Mas não é bem assim. Ousamos dizer que na Biblioteca de Borges os livros parecem mais concretos do que os livros e 
informações computadorizadas existentes em certas análises acadêmicas. A partir do qualificativo virtual, tudo se explica, como se a comunicação em rede existisse fora do tempo e do espaço, sem trabalho e sem guardiões e sem as tensões de acesso ao conhecimento.

A diferença apontada por muitos autores (Negroponte, 1997; Kroker, 1997) de que os livros antigos e os arquivos eram feitos de átomos e os livros e bancos de dados atuais são feitos de bits é útil. Mas livro ou banco de dados não são apenas bits ou átomos. Podemos abrir aqui duas frentes de argumentações, umạ relacionada com o processo produtivo e outra com o contexto da produção.

A primeira diz que a informação e a cultura tornaram-se um elemento específico da valorização do capital. Miege reconhece a pequena quantidade de trabalhos teóricos que tratam do problema, ajuntando que toda discussão deveria passar pela ausência ou presença de trabalho produtivo - aquele que cria a maisvalia: "a partir desta perspectiva, se o trabalho (cultural) é produtivo ou improdutivo não é determinado pelo conteúdo mas pelo lugar que ele ocupa nas relaçōes de produção" (Miege, 1989, p.25).

Se seguirmos essa perspectiva, muito poderá ser dito a respeito do tipo de trabalho requerido em um arquivo ou em uma biblioteca moderna, onde começam a desaparecer as fronteiras de atividades dos dois setores. E aqui entra a segunda frente. E começaremos a partir da argumentação de um arquivista, Richard Hermans, sobre duas profissões que ele considera predestinadas a terem um único futuro: os arquivistas e os bibliotecários.

A era de informação digital torna fluidos e embaralhados os limites entre diversas fontes e provedores de informação. Informação pura é o que conta atualmente, independente do background e origem das fontes e independente de quem provê a desejada informação (Hermans, 1996, p. 18).

A afirmação é procedente se analisada numa pragmática moderna da arquivologia ou da biblioteconomia mas não satisfaz quando se busca uma compreensão contextualizada do trabalho, das condições de produção e do produto chamado informação. A convergência de duas profissões só pode ser realmente entendida no contexto de seus objetivos, nas características da produção ou reprodução da informação, na sua localização nas relações de produção e nas mudanças institucionais dos arquivos das bibliotecas em nível local, regional ou internacional. 
No mesmo artigo, Hermans reconhece dois conceitos que envolvem a arquivística. Um, que enfatiza a função administrativa e jurídica dessa profissão, e outro, seu papel sociocultural. Abre, assim, uma janela para o reconhecimento de que um sistema de arquivos ou uma biblioteca, um livro ou uma ficha não são apenas suportes que levam conteúdo mas a cristalização de certas práticas culturais ao longo dos séculos. E hoje, integrando o setor florescente das indústrias da informação ou da cultura, essas práticas também são econômicas.

"A noção de que livros impressos são espaciais e textos no computador são temporais equivale a assumir que ondas de rádio não são físicas porque não podemos vê-las. Os textos na tela do computador não levitam nem estão suspensos em algum universo paralelo. Textos nos computadores existem em algum tipo de memoria muito real, embora invisivel-RAM, ROM ou cache (Kroker, Arthur e Marilouise, 1997, p. 1).

Quando acessamos em rede algum banco de dados, estamos deflagrando uma série de práticas produtivas, algumas delas em dimensão industrial, que tornou possível esse acesso. A virtualidade é apenas uma parte - e numa perspectiva mais focalizada, a parte menos importante - desse processo de produção. É bem verdade que essa imaterialidade, decorrente da revolução da microeletrô. nica, trouxe a vantagem de que qualquer pessoa, munida de um computador, um programa e com acesso ao sistema de telecomunicações possa se comunicar em rede. Essa participação lhe proporciona coletar informações das mais diversas fontes sobre os mais diversos temas, falar com pessoas no mundo inteiro, participar de discussões, disseminar informações de todos os tipos, das políticas dos zapatistas na selva mexicana às de um movimento ambien. talista Inuit.

Como, porém, não só as informações como também os próprios sistemas produtores de informação inexistem no vácuo, as discussões no países em desenvolvimento levam necessariamente o contexto do acesso. A informação e a comunicação se globalizaram, o acervo da biblioteca do Congresso dos Estados Unidos e de outras bibliotecas internacionais se materializa na tela do computador. E num país onde rareiam bibliotecas, certa elite afluente vai visitar bibliotecas virtuais do exterior, de acesso público, sem nunca ter entrado numa biblioteca pública de seu próprio país.

Esse fato acontece porque os países periféricos têm limitada a 
sua incorporação à cultura e à informação global. Numa análise sobre consumo, Canclini observa que em muitos países

“...o acesso ainda é exclusivo à primeira etapa das indústrias audiovisuais: os programas de entretenimento e a informação que circula pelo rádio e pela televisão de acesso gratuito. Alguns grupos (minoritários) das classes médias e populares puderam atualizar e sofisticar a sua informação como cidadãos ao participar de uma segunda etapa no uso dos meios de comu. nicação, que abrange os circuitos de televisão a cabo, educação ambiental e sanitária, a informação política através do vídeo etc." (Canclini, 1995, p. 212).

Ele conclui que só pequenas faixas das elites empresariais estão conectadas às formas mais ativas de comunicaçāo, isto é, a esse terceiro sistema que inclui o fax, o correio eletrônico, as antenas parabólicas e o intercâmbio lúdico que se estendem desde a filmagem de vídeo-amadores até a construção de redes internacionais de tipo horizontal. Acreditamos que essa observação de Canclini é importante no contexto dos países da América Latina, especialmente no caso brasileiro, que vive uma euforia com a instalação dos modernos meios de comunicação e informação.

Falamos em comunicação em redes e relacionamos o seu uso com o reforço da exclusão. No entanto, pelo que vimos, não são as tecnologias que excluem mas o contexto de seu uso. A exclusão vem antes e se localiza no modelo econômico ou político escolhido. E mesmo dentro desse modelo, há espaços para a construção de uma nova hegemonia em que exista mais igualdade e em que o acesso à comunicação em rede seja possível a outros camadas da sociedade.

O discurso da exclusão em relação à tecnologia existiu - ou poderia ter existido - por ocasião do surgimento da televisão, quando a ela tinha acesso apenas um reduzido contingente da sociedade. Os aparelhos receptores eram caros e os programas não diziam respeito à maioria da população, que não dispunha nem mesmo de eletricidade. A própria lógica da produção, no entanto, fez com que hoje a televisão seja o aparelho mais encontrado nos lares brasileiros. Em outras palavras, os domicílios contam muitas vezes com televisão mas não dispõem de geladeiras. Os preços caíram e estão caindo. E o mesmo se pode dizer com a comunicação em rede, onde, em alguns países, existem terminais de uso comunitário não apenas em escolas mas em correios, bibliotecas e em 
outros espaços públicos.

Além disso, a história da Internet mostra que, por motivos diversos, que não nos cabe aqui analisar, sua configuração e sua horizontalidade possibilita uma maior participação do usuário. Existe, sim, a necessidade de um provedor, mas a interatividade que ela possibilita, a criação de novos espaços de sociabilidade, a emergência de um novo espaço público descentralizado e, pelo que tudo indica, de maiores dificuldades para seu controle, abrem um horizonte novo para a comunicação.

A multiplicação de sites eletrônicos capazes de levar ao mundo inteiro a voz de grupos oprimidos é uma prova de que as reflexões de Enzensberger sobre o uso das novas tecnologias pela sociedade são mais plausíveis agora do que nos anos 60 (Enzensberger, 1976). As páginas virtuais do movimento zapatista, da guerra da Bósnia, dos homossexuais ou de grupos étnicos, disponiveis na comunicação em rede, são uma mostra de que as potencialidades de uma comunicação horizontal e democrática são mais promissoras nas redes de comunicação do que na televisão, esta sim, verticalizada.

\section{Produção de imagens}

É cada vez mais rápida a descoberta de novas tecnologias e sua disponibilidade no mercado. Os lançamentos são instantâneos na economia globalizada. A passagem da economia fordista para a acumulação flexível facilitou essa estratégia de um tempo hegemônico único, ou seja, o tempo das multinacionais, das grandes corporações, que se reproduzem em áreas metropolitanas e mesmo no campo dos países em desenvolvimento. São espaços de grande densidade de ações, de troca de informaçōes e de mensagens. Essas novas tecnologias podem ser avaliadas de diversas formas, desde a densidade de linhas telefônicas em determinado bairro ou centro comercial, até o número de caixas eletrônicos ou assinantes plugados na Internet. Santos afirma que na verdade o tempo não é único mas descontínuo, pois ao lado desse tempo hegemônico existe um tempo hegemonizado, numa dinâmica espacial reveladora de uma dinâmica social. Ele chega a se perguntar:

Que é, assim, esse Tempo do Mundo? Isso existe? Nós sabemos que há apenas um relogio mundial, mas não um tempo mundial. Seja como for, a distância do homem comum em relação a esse novo Tempo do Mundo é maior, muito maior do que antes. A mundialização multiplica o número de vetores 
e, na verdade, aumenta as distâncias entre instituições e pessoas. Ubiqüidade, aldeia global, instantaneidade são, para o homem comum, apenas uma fábula. (Santos, 1996, p.83).

A contradição da aldeia global nos países em desenvolvimento pode ser quantificada. Uma pesquisa nacional feita pelo jornal Folha de S. Paulo revela alguns dados interessantes sobre os excluídos. Segundo a pesquisa esse contingente chega a $59 \%$ da população do país, a maioria deles não passando do oitavo grau na escola e com renda familiar de menos de $\mathrm{R} \$ 120,00$. Nesse grupo, $56 \%$ são brancos; $33 \%$, pardos; $9 \%$, negros; e $2 \%$, de outras etnias. No outro extremo dessa divisão da população em cinco grandes grupos encontra-se uma elite, integrada por $8 \%$ dos brasileiros. Desse contingente, $74 \%$ cursaram a universidade; $64 \%$ ganham mais de 20 salários mínimos por mês; $85 \%$ são brancos; $12 \%$, pardos; e $1 \%$ de outras etnias (Toledo, 1997).

Esses dados demonstram que estamos nos encaminhando para o último ponto sobre o qual nos propusemos a refletir, ou seja, o reforço da lógica da exclusão nos países em desenvolvimento em relação às novas tecnologias do conhecimento. Os $59 \%$ de excluídos ainda continuam sem acesso à informação, numa divisão entre informados e desinformados, entre os que podem pagar pela informação e os que não o podem. Uma biblioteca tradicional ou um arquivo histórico, de onde esse contingente de pessoas já fora excluído, constituíam-se, pela sua lógica, em uma promessa de acesso democrático às informações. As bibliotecas virtuais, apesar de todos os seus benefícios, trabalham com a lógica da exclusão em países como o Brasil, devido ao pagamento necessário ao provedor, devido aos equipamentos e pelas tendências de uma lógica de mercado para os arquivos on line dos jornais ou das bibliotecas.

Para comparar os dados da pesquisa sobre os excluídos no país com os recentes assal tos à rede pela economia de mercado, vamos nos voltar, brevemente, para três experiências em andamento: a da Biblioteca Britânica, a da Biblioteca da França e a da Biblioteca do Congresso, todas elas relatadas por Browning (1997).

1. A nova Biblioteca da França, inaugurada por Mitterrand poucos meses antes de sua morte, tem como objetivo um equilíbrio entre conservação e difusão. Um projeto em andamento iniciou a 
digitalização das imagens de 100 mil cânones do século XX, escolhidos por um conselho especial. Qualquer usuário francês munido de computadores potentes com boa conexão em redes terá acesso a esse material. Brevemente, esse serviço estará disponivel a qualquer pessoa, em toda parte do mundo.

2. A Biblioteca Britânica e o Document Supply Center, em Boston Spa, no Yorkshire, com 12 a 15 milhões de entradas, oferecem serviços básicos grátis, com acesso a salas, catálogos e livros, som, mapas e coleções, sendo a reprodução de numerosos documentos ao preço de custo. No entanto, essa instituição diversifica a sua oferta. Ele já recebe CD-ROMs dos editores, com imagens digitalizadas de artigos. Toda vez que um usuário faz um pedido, tira-se uma cópia. Boa parte do orçamento da biblioteca provém dessas vendas, especialmente de usuários estrangeiros. Para se dar a dimensão da venda de informações, um terço do orçamento anual de 150 milhões provém dessas vendas, reacendendo as discussōes sobre direitos autorais.

3. A Biblioteca do Congresso dos Estados Unidos, com $20 \mathrm{mi}$ lhões de entradas, vem oferecendo duplicação de documentos a preço de custo, acrescido de mais $10 \%$, permitidos por lei. Contagiada com as mudanças no campo das indústrias da informação, a Biblioteca do Congresso quer mudar essa lei que estabelece um limite para os lucros. Há uma forte oposição das Associações das Indústrias da Informação, que temem concorrência desleal devido aos subsídios.

Com exceção da experiência francesa, as experiências britânica e norte-americana mostram a entrada de duas instituições tradicionais nas regras do mercado. Em outras palavras, as bibliotecas, até agora guardiãs das tradições, vão se transformar em eixos dessas mudanças, "caindo as paredes e dissolvendo a barreira entre os editores e os bibliotecários" (Brown, 1997). Essa lógica do mercado adotada por parte dessas duas grandes bibliotecas provoca discussões sobre o possível deslocamento dessas instituições, até então com um papel social e cultural importante, para o setor das indústrias culturais. Em outras palavras, como observa Brown, se não cobram, criam problemas com os editores e são acusadas de concorrência desleal; e se cobram, essas instituições fogem de seu papel tradicional, que é o de democratizar o acesso à informação.

Schiller nota que o debate sobre a mercantilização do ciberes- 
paço está apenas começando (Schiller, 1997, p.24 e 25). Essa tendência está mais clara nos espaços criados pela convergência da comunicação e das telecomunicações, em que Murdoch, Time Warner, CNN, Microsoft e a Hughes Corporation, da GM, investem bilhões de dólares em sites, esperando que sejam rentáveis no futuro. A segunda tendência é a utilização de financiamento indireto através da publicidade. Nesse caso, os usuários da Biblioteca Britânica, da do Congresso ou da Fundação Biblioteca Nacional, do Rio de Janeiro, teriam acesso gratuito ao acervo, passando antes por uma publicidade interativa de um novo creme ou de qualquer geringonça eletrônica. É bom lembrar que essa solução já está sendo utilizada em outras experiências, como os jornais eletrônicos ou a televisão on line.

\section{De volta a Babel}

Na Biblioteca de Babel, segundo Borges, em cada lado de um saguão de cada galeria havia dois sanitários minúsculos, num dos quais o bibliotecário podia dormir de pé. Quando se lê essa informação - as ficçōes são cheias de informações - espera-se que as relações de trabalho na Biblioteca de Babel tenham melhorado muito, especialmente depois que um demiurgo sonhou um sonho dentro de um sonho em que ela seria disponível em rede.

Relendo-se a descrição da Biblioteca de Babel, damo-nos conta de que essa afirmação continua verdadeira numa biblioteca sem paredes. Por um motivo simples: sem paredes, o bibliotecário se perde entre as prateleiras virtuais que preenchem os hexágonos do conhecimento. Os textos multiplicam-se indefinidamente, pois ele não consegue mais controlar as entradas, as saídas, nem normatizá-los com segurança, sem que os guardiões possam reagir. $O$ ciberespaço pode the parecer uma nova Babel freqüentada por flâneurs e por desclassificados, onde o livro perdeu seu caráter sagrado e o conhecimento esqueceu-se dos antigos rituais. E o usuário entra nu ou bêbado, descomposto ou voyeur, dessacralizando o livro diante de olhos a tônitos. Enfim, no fundo desse ciberespaço, o bibliotecário vive um momento de transição, o momento da grande transiçāo do poder. O bibliotecário também foi desterritorializado.

A perplexidade nessa fase de transição tem analogia com a evolução dos primeiros bibliotecários. Os monges, diz Browning (1997), colecionavam livros e os conservavam para o uso comum. Faltava-lhes um sistema de organização para que esses mesmos 
livros pudessem ser encontrados mais tarde. Já os monges de nossas bibliotecas virtuais - e também os usuários - vivem soterrados sob o aluvião das informacões, têm consciência de que precisam classificar essas in formaçōes, interconectá-las, mas não conseguem nem controlar o seu fluxo nem impor uma ordem.

Talvez ele sinta uma nostalgia dessa ordem, conquistada depois de tão grande esforço. Como um monge antigo sobressaltado com o grande número de títulos que ele não pode classificar, o monge virtual vive a nostalgia de uma ordem preexistente. Ele talvez sonhe com o eterno viajante de Babel: se ele atravessasse a biblioteca em qualquer direção, comprovaria ao fím dos séculos que "os mesmos volumes se repetiriam na mesma desordera - que, reiterada, seria uma ordem: a Ordem". E exclamaria: "Minha solidão alegrase com essa elegante esperança" (Borges, 1976, p. 70). Bem diferente de uma biblioteca virtual febril, cujos fortuitos volumes correriam o incessante risco de se transformarem em outros, e que tudo afirmariam, negariam e confundiriam, como uma divindade delirante (Borges, 1976, p. 68).

\section{Bibliografia}

BORGES, J. L. Fiç̧öes. Porto Alegre, Editora Globo, 1976.

BROWNING. John. What is the role of libraries in the Information Economy? Disponfvel em 12 de julho de 1997 no seguinte endereço: http:// www. Wired.com/wired/I.l/features/libraries/html

DOWBOR, L. Os novos espaços do conhecimento. Transinformação, v.7, n. 1/2/ 3 (janeiro/dezembro de 1995) 15.32.

ENZENSBERGER, H. M. Elementos para uma teoria dos mídias. Rio, Tempo Brasileiro, 1976.

HARveY, D. A condição pós.moderna. Sáo Paulo, Loyola, 1992.

HERMANS, R. Two professions, onde future: archivists and librarians. IFLA Journal, v. 23, n.1 (1997) 17.19.

KROKER, Arthur e Marilouise. The book is dead, long live the book. In Theory, Technology and Culture, vol. 20, n 1 e 2 (julho 1997), dispon(vel on-line no seguinte endereço: http://www.ctheory.com.

NEGROPONTE, N. Bits and atoms. Disponivel em 2jul97 no seguinte endereç: http://wired/3.01/departments/negro.

SANTOS, Milton. Técnica, espaço, tempo. Globalizaçăo e meio técnico-científico informacional. Sao Paulo, Hucitec, 1996.

Paulo, Hucitec, 1996.

A natureza do espaço. Técnica e tempo, razao e emoçao. São

SCHILLER, D. Les marchands l'assaut d'Internet. Le Monde Diplomatique, março de 1997, páginas 24 e 25.

TOLEDO, J. R.Excluídos sáo $59 \%$ da populaçao do país, no caderno 1 da Folha de São Paulo, 13jul1997. 